\title{
A Systematic Literature Review of Consistency among Business Process Models
}

\author{
Afef Awadid, Selmin Nurcan \\ ${ }^{1}$ University of Paris 1 Pantheon-Sorbonne, CRI, France \\ \{nurcan@univ-paris1.fr, afef.awadid@malix.univ-paris1.fr\}
}

\begin{abstract}
The field of business process modeling has been beset by inter-model consistency problems which are mainly due to the existence of multiple variants of the same business process, for instance when models have been produced by different actors, or through the time by a same (or different) actor(s), as well as the possibility of its modeling from discrete and complementary perspectives (using different lenses). The aim of our research is manifold. First we aim to develop a framework (i) enabling situating new research activities as well as the existing approaches and (ii) targeting to master the inter-model consistency issue. Second, this framework shall offer the capability of handling business process models coherence issue (i) having in mind various modeling goals and targets/products and (ii) having in hand a wide range of problem statements and project situations requiring the use of a large catalogue of business process meta-models. Third, we have the ambition of determining gaps in current research with the aim of suggesting areas for further investigations in the area of inter-models consistency. In order to do so, this paper presents a systematic literature review (SLR) of consistency among business process models, where a total of 982 published papers extracted from the most relevant scientific sources, were considered, of which 41 papers, were ultimately included.
\end{abstract}

Keywords: Business process models, modeling perspectives, inter-model consistency, systematic literature review

\section{Introduction}

Business process modeling is chiefly a convergence of two connected modeling disciplines: process modeling [1, 2, 3], which aims at providing "an abstract representation of a process architecture, design or definition" [4] and enterprise modeling, which seeks to provide a full and holistic understanding of the enterprise [5], [70]. Reasons for this convergence might be (i) the key role played by business process (BP) models in both enterprise information systems development [6], and organizational management $[7,8]$, (ii) the similarity between these disciplines in that both may focus on business processes as subject of investigation by capturing the relevant ones [5], and (iii) both have been beset by inter-model consistency problems.

In the field of process modeling, these problems are mainly due to (a) the existence of multiple models or views, which take part in the information systems engineering [69] and (b) the existence of many variants of BP models, which capture the occurrences of the same BP. The inconsistencies caused by (a) are the root causes of many errors in the resulting software applications [9], while those caused by (b) constitute a serious obstacle "to dynamically switch process execution from one variant to another if required" [10]. The importance of the first family (a) of inter-model consistency problems is reported in a systematic review of UML model consistency 
management [11], and a survey on inconsistency management in software engineering [12]. The necessity of dealing with the second family (b) of consistency problems is proved by a large amount of work within this scope.

Similarly, in the field of enterprise modeling, consistency problems are of a great interest to both practitioners and researchers. This interest has emerged from the advent of multi-perspective or multi-view modeling methods where a complex system (e.g., the enterprise architecture, a BP) is captured from different perspectives (views) in order to master its complexity.

Although a SLR [11] and a survey [12] on the inconsistency management of software process models were already carried out and even though software processes are considered as business processes [13, 14], the existing work is mostly related to a particular kind of modeling approaches [15] (mainly object-oriented approaches). This is not the case in BP modeling for which none of the modeling notations is predominant [16] until 2006. This broader extent of the notion of inter-model consistency requires the capability of positioning the great amount of research works in this scope with respect to a reference framework that facilitates identifying the emerging/unresolved problems in the area of inter-model consistency in BP modeling.

Carrying out a Systematic Literature Review (SLR) in this area seems to be appropriate to set up such a framework. In fact a SLR is defined as a means of identifying, evaluating and interpreting all available research relevant to a particular research question or topic area with the aim, amongst others, of providing a framework (background in order to properly position new research activities [17]).

In this paper, we undertake the first SLR for inter-model consistency in the field of BP modeling. We aim at providing a generic framework enabling positioning existing approaches and determining gaps in the current research. The remainder of the paper is structured as follows. Section 2 outlines the key terms and concepts with regard to the topic of inter-model consistency. We describe our methodology in section 3 and present the results and answer our research questions in section 4 . We present the framework in section 5. Section 6 concludes the paper.

\section{Inter model consistency: Key terms and concepts}

Consistency issues have been raised in various domains such as databases, information systems development, enterprise modeling and software engineering. Thereby, manifold are the approaches proposing definitions for concepts in this area. Hence, in order to establish a common understanding of the terminology used in this paper, we start by defining key concepts on which this SLR is grounded.

- Diagram: a graphical representation of real world using a particular modeling language.

- Perspective: refers to the notion of view defined as a representation of a system (e.g. a BP) from the angle of a related set of concerns or aspects [18]. For instance informational, functional, behavioral, organizational, operational and intentional in [71].

- Consistency among models: refers to the fact that the information covered in each model should not contradict each other [19]. For instance, if the concept actor appears in more than one model, its instances in all corresponding models have to be syntactically and semantically equivalent.

- Multi-perspective modeling: refers to the notion of multi-view modeling defined as 
the construction of distinct and separate models of the same system in order to model different aspects of it [20]. For instance, in the domain of business processes, multiperspective modeling allows us to depict the same BP using distinct and complementary representations adopting distinct modeling languages.

- Projective multi-perspective modeling (commonly referred to as projective multiview modeling): one comprehensive overarching meta-model is given. All perspectives captured by all concerned modeling languages are defined as projections onto this central meta-model [21]. One example of this approach is the UML, which has, in its current version the Meta Object Facility (MOF) as a common meta-model. All UML diagram types (e.g. activity diagrams, sequence diagrams) are specified by projections onto that MOF meta-model.

- Selective multi-perspective modeling (commonly referred to as selective multi-view modeling): no central meta-model is given. Each perspective is captured by a distinct meta-model and the overall system is obtained as synthesis of the information carried out by the different meta-models [21]. Hence, if one concept (e.g. activity) is used in multiple perspectives, the dependencies between them need to be specified manually.

- Horizontal consistency: refers to the consistency between models at the same phase or abstraction level [22]. For instance, the consistency between two BPMN models produced during the analysis phase.

- Vertical consistency: refers to the consistency between models at different development phases or abstraction levels [22]. For example, the consistency between a BPMN analysis model and the associated BPMN implementation model.

- Syntactic consistency: refers to ensure that a model conforms to its abstract syntax specified by its meta-model [23]. For instance, the roles in the actor-role model should appear in the corresponding role-activity model.

- Semantic consistency: refers to the fact that models behavior should be semantically compatible [23]. For example, actors in the actor-role model have to be defined as business objects in the corresponding business objects model.

\section{Method applied for the SLR}

In order to conduct this study as a SLR, we have relied on the review protocol used in [24], since it was based on the original guidelines as proposed by Kitchenham [25]. Two key concepts are mainly associated with the notion of SLR namely (i) the primary study which refers to an empirical study investigating a specific research question and (ii) the secondary study referring to the study that reviews all the primary studies relating to a specific research issue with the aim of integrating / synthetizing evidence related to that issue [25]. The present study is then categorized as a secondary study and involves the steps cited below.

\subsection{Research questions and search process}

This SLR raises the research questions listed below resulting from our understanding of the key points after the study of the literature.

RQ1. What can be a source of inconsistency among BP models? 
RQ2/RQ3. What type(s) of diagram(s) are being tackled? (i) activity-driven diagrams describing a BP as a sequence of activities, (ii) role-driven ones specifying the roles and the organization related issues involved in the BP and/or (iii) product-driven ones that represent a BP through its products/results (or resources) and their evolution. And how many diagrams have been used?

RQ4/RQ5. On which type of inter-model consistency problem focuses the study? : Horizontal or vertical and what is the nature of the targeted consistency? : Syntactic, semantic or both.

RQ6. What is the main methodological activity [11] on which the consistency management process relies?

RQ7/RQ8. What is the scope of business process models under study? Intra-enterprise or inter-enterprise models and what kinds of multi-perspective modeling are being addressed? Selective or projective multi-perspective modeling.

To perform the manual search process for primary studies, we based on a set of sources that were recommended in [26] as relevant within the research community and that were appropriate for the present study. These sources along with the search fields are presented in Table 1. In the aforementioned sources, we tested with different search string criteria. That which ultimately allowed obtaining the highest number of relevant results was:

(“business process model” AND (“consistency” OR “inconsistency”))

Table 1. Selected sources along with research fields

\begin{tabular}{lr}
\hline \multicolumn{1}{c}{ Source } & \multicolumn{1}{c}{ Search field } \\
\hline Google Scholar & Title, abstract and full text \\
ACM Digital Library & Title, abstract and full text \\
Science Direct & Title, abstract and full text \\
SCOPUS Database & Title, abstract and keywords \\
IEEE Computer Society & Title, abstract and full text \\
\hline
\end{tabular}

In the search process, we also took into account the synonyms and terms related to each of the three concepts, as shown in Table 2.

Table 2. Other synonyms and terms used in the search process

\begin{tabular}{cc}
\hline Concept & Synonym and/or related term \\
\hline Business process model & $\begin{array}{c}\text { process model; process variant; } \\
\text { enterprise modeling or enterprise modeling; } \\
\text { multi-perspective modeling or multi-perspective modeling; } \\
\text { multi-view modeling or multi-view modeling }\end{array}$ \\
\hline Inconsistency & inconsistencies: incoherence: incohesion \\
\hline
\end{tabular}

\subsection{Inclusion/exclusion criteria and quality assessment}

In this study, peer reviewed papers with the following concerns were included:

- Papers proposing approaches that favor or evaluate consistency between BP models; each included paper raise one of the following questions: how to check consistency between BP models or how to maintain consistency between BP models.

- Papers where the proposed approach was based on the comparison of two or more BP models depicting the same BP, since such comparison is the cornerstone of each 
inconsistency management activity. For instance, papers dealing with the verification of similarity between BP models are included.

- Papers dealing with the issue of consistency in the context of multi-perspective modeling with a particular focus on the consistency among BP models or with a wider focus towards enterprise modeling.

Articles with the following concerns were excluded:

- Papers focusing on the issue of compliance defined as "a relationship between two sets of specifications: the specifications for executing a BP and the specifications regulating a business" [27]. Thus only papers where the models in question depict the same BP as subject of modeling have been considered.

- Papers dealing with the topic of inter-model consistency, where the subject under study is the software process. This means that our study is not concerned with the inter-model consistency in the field of software engineering.

We also excluded books, doctoral dissertations and non-English papers focusing on the topic of inter-model consistency.

The activity of assessing the "quality" of primary studies is generally viewed as important mainly in guiding the interpretation of findings and determining the strength of inferences as well as in guiding recommendations for further research [25]. The main criteria on which we based the quality assessment of the primary study were (QA1) "is the inter-model consistency the main purpose of the paper in such a way that the issue is studied in a thorough manner, contextualized and validated?", and (QA2) "is the proposed approach generalizable and to which extent is it applicable in another context?" The questions were scored as follows:

QA1. Y (yes), the inter-model consistency problem was contextualized, a well-defined approach was proposed in order to solve it, and a validation of the approach was provided and supported with a tool; P (Partly), the problem was contextualized, a welldefined approach was proposed, a first manual validation was given, but no support tool was offered; $\mathrm{N}(\mathrm{No})$, the approach was defined in a general and a succinct way and no validation was given.

QA2. Y (yes), the proposed solution is likely to be applicable outside of the primary study; P (Partly), the proposed solution needs to be slightly altered to meet other requirement outside of the study; $\mathrm{N}$ (No), the proposed solution is not likely to be applicable outside of the study (i.e. it is limited to a narrow context).

The scoring procedure was $\mathrm{Y}=1 ; \mathrm{P}=0.5 ; \mathrm{N}=0$. In the coordination between the two authors with regard to the stages of the data collection as well as the quality assessment, each author played a particular role. The one applied inclusion and exclusion criteria during data collection, assessed the quality of primary studies and checked manually the excluded papers based on the abstracts and introduction sections. The other checked all included papers and their score. In case of doubt of the former and lack of availability of the latter to perform a deeper verification, we contacted the authors of the paper.

Data collection and data analysis: The data we extracted from each primary study are: (i) the source, where the paper was found.; (i) the data related to the research questions we have raised in section 3.1; (iii) quality evaluation. The data was tabulated in order to put emphasis on the research questions listed in Section 3.1. 


\section{Results}

In this section, we summarize and analyze the results of our SLR. We discuss the answers to our research questions and provide recommendations.

\subsection{Search results}

Table 3 shows the results of the search procedure respectively before and after applying inclusion and exclusion criteria, along with the selected papers. Before applying the exclusion criterion for eliminating papers that deal with inter-model consistency in the field of software engineering, the number of studies in the first round was very large (982). Applying the aforementioned criterion has considerably decreased this number. This implies that the inter-model consistency is a widely-tackled topic in the field of software engineering. In order to avoid biasing the results of the data analysis, it was essential to ensure that papers appeared in multiple sources were taken into account only once (leading to 982). Also, among the 41 resulting papers the ones describing the same approach were grouped together (leading to 36 as shown in Table 4).

Table 3. Summary of results before and after applying inclusion and exclusion criteria.

\begin{tabular}{lcccccc}
\hline & IEEE & Scopus & Google Scholar & ACM & Science Direct & Total \\
\hline Results before & 192 & 12 & 678 & 24 & 76 & 982 \\
Results after & 9 & 0 & 24 & 2 & 6 & 41 \\
Selected papers & {$[28,33,-$} & {$[29-32,35-37$,} & {$[50,53]$} & {$[39,40$,} & \\
& 34,38, & $41-46,51,52$, & & $54,62-64]$ & \\
& $47-49$, & $55-58,60,61$, & & & \\
\hline
\end{tabular}

Thereby, the total number of approaches considered during the data analysis and evinced in Table 4 is 36 . The aforesaid Table 4 puts emphasis on the first part of data extracted from each primary study. It includes data related to the source of inconsistency (RQ1), the type (RQ4) and nature (RQ5) of consistency, the type of multi-view modeling (RQ8), the type of diagrams (RQ2), the number of modeling techniques used (RQ3), the scope of BP models (RQ7), and the main activity (purpose) on which the consistency management relies (RQ6). Regarding the latter we identified six fundamental activities in consistency management:

(i) Detect common concepts refers to determining the concepts shared between several models;

(ii) Establish correspondences between elements of models refers to making correspondence between pairs of elements (mainly activities) between two models;

(iii) Evaluate consistency between models refers to checking whether two models are consistent (they do not contradict each other);

(iv) Generate views dependency model refers to generating an intermediate model, which captures the common concepts between multi-perspective models;

(v) Evaluate views dependency model with regard to consistency rules refers to verifying whether the view dependency model complies with the defined consistency rules;

(vi) Generate model from another refers to transforming one model to another. 
Table 4. Summary: The first part of extracted data related to the inter-model consistency.

\begin{tabular}{|c|c|c|c|c|c|c|c|c|c|}
\hline ID & Reference & $\begin{array}{l}\text { Inconsistency } \\
\text { source } \\
\text { (RQ1) }\end{array}$ & $\begin{array}{l}\text { Consistency } \\
\text { type } \\
\text { (RQ4) }\end{array}$ & $\begin{array}{l}\text { Consistency } \\
\text { nature } \\
\text { (RQ5) }\end{array}$ & $\begin{array}{c}\text { Type of } \\
\text { multi-view } \\
\text { modeling } \\
\text { (RQ8) }\end{array}$ & $\begin{array}{l}\text { Diagram } \\
\text { type } \\
\text { (RQ2) }\end{array}$ & $\begin{array}{l}\text { Number of } \\
\text { modeling } \\
\text { techniques } \\
\text { (RQ3) }\end{array}$ & $\begin{array}{c}\text { BP } \\
\text { models } \\
\text { scope } \\
\text { (RQ7) } \\
\end{array}$ & $\begin{array}{l}\text { The main purpose of inconsistency } \\
\text { management } \\
\text { (RQ6) }\end{array}$ \\
\hline S1 & Bork et al, [28] & $\begin{array}{l}\text { Multi-persp. } \\
\text { modeling }\end{array}$ & Horizontal & $\begin{array}{l}\text { Syntactic } \\
\& \text { Semantic }\end{array}$ & Projective & DSML & 4 & Intra- & Generate intermediate model (iv) \\
\hline S2 & Bork et al, [44] & $\begin{array}{l}\text { Multi-persp. } \\
\text { modeling }\end{array}$ & Horizontal & $\begin{array}{l}\text { Syntactic } \\
\& \text { Semantic }\end{array}$ & Projective & DSML & 4 & Intra- & Detect common concepts (i) \\
\hline S3 & Yan et al, [29] & $\begin{array}{l}\text { Multi-persp. } \\
\text { modeling }\end{array}$ & Horizontal & $\begin{array}{l}\text { Syntactic } \\
\& \text { Semantic }\end{array}$ & Projective & DSML & $\begin{array}{c}>1 \\
\text { (unknown) }\end{array}$ & Inter- & Detect common concepts (i) \\
\hline S4 & $\begin{array}{l}\text { Hallerbach et al, } \\
\text { [30] }\end{array}$ & $\begin{array}{l}\text { BP models } \\
\text { variants }\end{array}$ & Vertical & Semantic & - & Activity- & 1 & Intra- & $\begin{array}{l}\text { Establish correspondences between } \\
\text { models (ii) }\end{array}$ \\
\hline S5 & $\begin{array}{l}\text { Smirnov et al } \\
{[31]}\end{array}$ & $\begin{array}{l}\text { BP models } \\
\text { merging }\end{array}$ & Vertical & $\begin{array}{l}\text { Semantic } \\
\text { (behavioral) }\end{array}$ & - & Activity- & 1 & Intra- & Generate model from another (vi) \\
\hline S6 & $\begin{array}{l}\text { Koliadis } \\
{[32],[38]}\end{array}$ & $\begin{array}{l}\text { Multi-persp. } \\
\text { modeling }\end{array}$ & Horizontal & Semantic & - & $\begin{array}{l}\text { Activity- } \\
\text { Role- }\end{array}$ & 2 & Intra- & Evaluate intermediate model (v) \\
\hline S7 & Gerth et al, [33] & $\begin{array}{l}\text { BP models } \\
\text { merging }\end{array}$ & Vertical & $\begin{array}{l}\text { Semantic } \\
\text { (behavioral) }\end{array}$ & - & Activity- & 1 & Intra- & Generate model from another (vi) \\
\hline S8 & Zemni et al, [34] & $\begin{array}{l}\text { BP models } \\
\text { merging }\end{array}$ & Vertical & $\begin{array}{l}\text { Semantic } \\
\text { (behavioral) }\end{array}$ & - & Activity- & 1 & Intra- & Generate model from another (vi) \\
\hline S9 & $\begin{array}{l}\text { Pascalau et al, } \\
\text { [35] }\end{array}$ & $\begin{array}{l}\text { BP models } \\
\text { variants }\end{array}$ & Vertical & Semantic & - & Activity- & 1 & Intra- & Generate model from another (vi) \\
\hline S10 & $\begin{array}{l}\text { Pascalau et al, } \\
\text { [43] }\end{array}$ & $\begin{array}{l}\text { BP models } \\
\text { variants }\end{array}$ & Vertical & Semantic & - & Activity- & 1 & Intra- & $\begin{array}{l}\text { Establish correspondences between } \\
\text { models (ii) }\end{array}$ \\
\hline S11 & $\begin{array}{l}\text { Weidlich al, } \\
{[36],[56],[63]}\end{array}$ & $\begin{array}{l}\text { BP models } \\
\text { variants }\end{array}$ & Vertical & Semantic & - & Activity- & 1 & Intra- & Generate model from another (vi) \\
\hline S12 & $\begin{array}{l}\text { Koschmider et al } \\
\text { [37] }\end{array}$ & $\begin{array}{l}\text { BP models } \\
\text { variants }\end{array}$ & Vertical & Semantic & - & Activity- & 1 & Intra- & Generate model from another (vi) \\
\hline S13 & Milani et al, [39] & $\begin{array}{l}\text { BP models } \\
\text { variants }\end{array}$ & Vertical & Semantic & - & Activity- & 1 & Intra- & Generate model from another (vi) \\
\hline S14 & $\begin{array}{l}\text { Dijkman et al } \\
{[40],[49],[66]}\end{array}$ & $\begin{array}{l}\text { BP models } \\
\text { variants }\end{array}$ & Horizontal & Semantic & - & Activity- & 1 & Intra- & $\begin{array}{l}\text { Establish correspondences between } \\
\text { models (ii) }\end{array}$ \\
\hline S15 & Lu et al, $[41]$ & $\begin{array}{l}\text { BP models } \\
\text { variants }\end{array}$ & Vertical & Semantic & - & Activity- & 1 & Intra- & $\begin{array}{l}\text { Evaluate consistency between } \\
\text { models (iii) }\end{array}$ \\
\hline S16 & $\begin{array}{l}\text { Rastrepkina et al, } \\
{[42]}\end{array}$ & $\begin{array}{l}\text { BP models } \\
\text { variants }\end{array}$ & Vertical & Semantic & - & Activity- & 1 & Intra- & $\begin{array}{l}\text { Establish correspondences between } \\
\text { models (ii) }\end{array}$ \\
\hline S17 & $\begin{array}{l}\text { Cheng-Leong et } \\
\text { al [45] }\end{array}$ & $\begin{array}{l}\text { BP models } \\
\text { variants }\end{array}$ & Vertical & Semantic & - & Activity- & 1 & Intra- & Generate model from another (vi) \\
\hline
\end{tabular}




\begin{tabular}{|c|c|c|c|c|c|c|c|c|c|}
\hline S18 & $\begin{array}{l}\text { Chen-Burger } \\
{[46]}\end{array}$ & $\begin{array}{l}\text { Multi-persp. } \\
\text { modeling }\end{array}$ & Horizontal & $\begin{array}{l}\text { Syntactic } \\
\& \text { Semantic }\end{array}$ & Selective & $\begin{array}{l}\text { Activity- } \\
\text { Product- }\end{array}$ & 2 & Intra- & Evaluate intermediate model (v) \\
\hline S19 & Koehler, [47] & $\begin{array}{l}\text { BP models } \\
\text { variants }\end{array}$ & Vertical & Semantic & - & Activity- & 1 & Intra- & $\begin{array}{l}\text { Evaluate consistency between } \\
\text { models (iii) }\end{array}$ \\
\hline S20 & $\begin{array}{l}\text { Worzberger et al, } \\
\text { [48] }\end{array}$ & $\begin{array}{l}\text { BP models } \\
\text { variants }\end{array}$ & Vertical & Semantic & - & Activity- & 1 & Intra- & $\begin{array}{l}\text { Evaluate consistency between } \\
\text { models (iii) }\end{array}$ \\
\hline S21 & Lu et al, $[50]$ & $\begin{array}{l}\text { BP models } \\
\text { variants }\end{array}$ & Vertical & Semantic & - & Activity- & 1 & Intra- & $\begin{array}{l}\text { Establish correspondences between } \\
\text { models (ii) }\end{array}$ \\
\hline S22 & Gulden et al, [51] & $\begin{array}{l}\text { Multi-persp. } \\
\text { modeling }\end{array}$ & Horizontal & $\begin{array}{l}\text { Syntactic } \\
\text { \&Semantic }\end{array}$ & Projective & DSML & 3 & Intra- & Detect common concepts (i) \\
\hline S23 & Delen et al, [52] & $\begin{array}{l}\text { Multi-persp. } \\
\text { modeling }\end{array}$ & Horizontal & $\begin{array}{l}\text { Syntactic } \\
\& \text { Semantic }\end{array}$ & Projective & unspecified & unspecified & Intra- & Detect common concepts (i) \\
\hline S24 & Leist et al, [53] & $\begin{array}{l}\text { Multi-persp. } \\
\text { modeling }\end{array}$ & Horizontal & $\begin{array}{l}\text { Syntactic } \\
\text { \&Semantic }\end{array}$ & Projective & Activity- & 1 & Intra- & Detect common concepts (i) \\
\hline S25 & Shunk et al, [54] & $\begin{array}{l}\text { Multi-persp. } \\
\text { modeling }\end{array}$ & Horizontal & $\begin{array}{l}\text { Syntactic } \\
\& \text { Semantic }\end{array}$ & Projective & unspecified & unspecified & Intra- & Detect common concepts (i) \\
\hline S26 & Fang et al, [55] & $\begin{array}{l}\text { BP models } \\
\text { variants }\end{array}$ & Vertical & Semantic & - & Activity- & 1 & Intra- & $\begin{array}{l}\text { Evaluate consistency between } \\
\text { models (iii) }\end{array}$ \\
\hline S27 & $\begin{array}{l}\text { Koubarakis et al, } \\
\text { [57] }\end{array}$ & $\begin{array}{l}\text { Multi-persp. } \\
\text { modeling }\end{array}$ & Horizontal & $\begin{array}{l}\text { Syntactic } \\
\& \text { Semantic }\end{array}$ & Projective & unspecified & unspecified & Intra- & Evaluate intermediate model (v) \\
\hline S28 & $\begin{array}{l}\text { Vanderfeesten et } \\
\text { al, [58] }\end{array}$ & $\begin{array}{l}\text { BP models } \\
\text { variants }\end{array}$ & Vertical & Semantic & - & Activity- & 1 & Intra- & $\begin{array}{l}\text { Evaluate consistency between } \\
\text { models (iii) }\end{array}$ \\
\hline S29 & $\begin{array}{l}\text { Martens et al, } \\
\text { [59] }\end{array}$ & $\begin{array}{l}\text { BP models } \\
\text { variants }\end{array}$ & Vertical & Semantic & - & Activity- & 1 & Intra- & Generate model from another (vi) \\
\hline S30 & Decker et al, [60] & $\begin{array}{l}\text { BP models } \\
\text { variants }\end{array}$ & Vertical & Semantic & - & Activity- & 1 & Intra- & $\begin{array}{l}\text { Evaluate consistency between } \\
\text { models (iii) }\end{array}$ \\
\hline S31 & Fang et al, [61] & $\begin{array}{l}\text { BP models } \\
\text { variants }\end{array}$ & Vertical & Semantic & - & Activity- & 1 & Intra- & $\begin{array}{l}\text { Establish correspondences between } \\
\text { models (ii) }\end{array}$ \\
\hline S32 & $\begin{array}{l}\text { DeMedeiros et } \\
\mathrm{al},[62]\end{array}$ & $\begin{array}{l}\text { BP models } \\
\text { variants }\end{array}$ & Vertical & $\begin{array}{l}\text { Semantic } \\
\text { (behavioral) }\end{array}$ & & Activity- & 1 & Intra- & $\begin{array}{l}\text { Evaluate consistency between } \\
\text { models (iii) }\end{array}$ \\
\hline S33 & $\begin{array}{l}\text { Niemann et al, } \\
\text { [64] }\end{array}$ & $\begin{array}{l}\text { BP models } \\
\text { variants }\end{array}$ & Vertical & Semantic & - & Activity- & 1 & Intra- & $\begin{array}{l}\text { Evaluate consistency between } \\
\text { models (iii) }\end{array}$ \\
\hline S34 & Kuster et al, [65] & $\begin{array}{l}\text { BP models } \\
\text { variants }\end{array}$ & Vertical & $\begin{array}{l}\text { Syntactic } \\
\& \text { Semantic }\end{array}$ & - & Activity- & 1 & Intra- & $\begin{array}{l}\text { Evaluate consistency between } \\
\text { models (iii) }\end{array}$ \\
\hline S35 & $\begin{array}{l}\text { Van der Aalst et } \\
\text { al, [67] }\end{array}$ & $\begin{array}{l}\text { BP models } \\
\text { variants }\end{array}$ & Vertical & Semantic & - & Activity- & 1 & Intra- & $\begin{array}{l}\text { Evaluate consistency between } \\
\text { models (iii) }\end{array}$ \\
\hline S36 & Li et al, [68] & $\begin{array}{l}\text { BP models } \\
\text { variants }\end{array}$ & Vertical & Semantic & - & Activity- & 1 & Intra- & $\begin{array}{l}\text { Evaluate consistency between } \\
\text { models (iii) }\end{array}$ \\
\hline
\end{tabular}

DSML: Domain specific modeling language 


\subsection{Quality evaluation of primary studies}

We assessed the studies for quality based on the two quality assessment questions defined in the section 3.2. The score for each study is shown in Table 5.

Table 5. Summary: Quality evaluation of studies.

\begin{tabular}{|c|c|c|c|c|c|c|c|}
\hline Study & QA1 & QA2 & Total score & Study & QA1 & QA2 & Total score \\
\hline S1 & Y & Y & 2 & S19 & P & N & 0.5 \\
\hline S2 & P & Y & 1.5 & S20 & Y & P & 1.5 \\
\hline S3 & P & P & 1 & S21 & P & N & 0.5 \\
\hline S4 & P & P & 1 & S22 & P & N & 0.5 \\
\hline S5 & P & P & 1 & S23 & P & N & 0.5 \\
\hline S6 & P & P & 1 & S24 & P & N & 0.5 \\
\hline S7 & P & P & 1 & S25 & P & Y & 1.5 \\
\hline S8 & P & Y & 1.5 & S26 & Y & P & 1.5 \\
\hline S9 & P & P & 1 & S27 & P & N & 0,5 \\
\hline S10 & Y & P & 1.5 & S28 & Y & P & 1.5 \\
\hline S11 & Y & Y & 2 & S29 & Y & P & 1.5 \\
\hline S12 & P & P & 1 & S30 & P & Y & 1.5 \\
\hline S13 & P & P & 1 & S31 & Y & P & 1.5 \\
\hline S14 & P & Y & 1.5 & S32 & P & Y & 1.5 \\
\hline S15 & Y & P & 1.5 & S33 & P & P & 1 \\
\hline S16 & P & P & 1 & S34 & P & P & 1 \\
\hline S17 & P & N & 0.5 & S35 & P & Y & 1.5 \\
\hline S18 & Y & P & 1.5 & S36 & Y & P & 1.5 \\
\hline
\end{tabular}

\subsection{Analysis of results and discussion}

The column named "Inconsistency source" in the above Table 4, along with Fig. 1 reveal that mainly three sources (the multi-perspective modeling, the existence of many $\mathrm{BP}$ models variants depicting the same BP, and the merging of BP models) prompted researchers to deal with the issue of inter-model consistency.

Fig. 1 shows that the BP models variants as source of inconsistency is tackled by $64 \%$ of the studies ( 23 of 36 ), whereas the other sources are somehow overlooked. When focusing on this source in relation with the columns named respectively "Consistency type" and "Number of modeling techniques", a strong dependency can be deduced between them as shown in Table 6 .

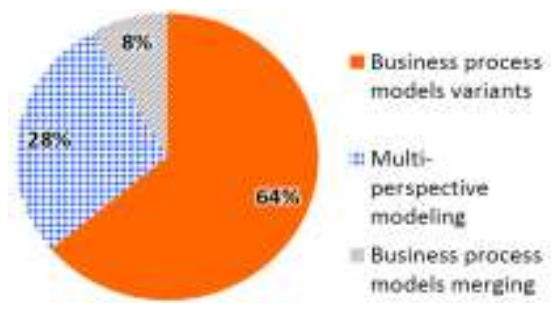

Fig. 1. Sources of inconsistencies addressed in literature

Table 6 reveals on one side that consistency problems caused by the existence of many variants of BP models are mainly vertical consistency problems $(95.7 \%)$, whereas those arising from the multi-perspective modeling as inconsistency source refer usually to horizontal consistency problems (100\%). On the other side, all primary studies dealing with consistency across BP models variants rely on one single modeling technique, whereas often more than one technique are (90\% of studies) used when the cause of 
inconsistency between models is the multi-perspective modeling.

Similarly, the nature of consistency can be strongly linked to the inconsistency source. Table 7 puts forward this link.

Table 6. Consistency type and number of techniques in relation with inconsistency source.

\begin{tabular}{|c|c|c|c|}
\hline \multirow[t]{2}{*}{ Inconsistency source } & Consistency type & \multicolumn{2}{|c|}{ Number of modeling techniques } \\
\hline & Horizontal & $=1$ & $>1$ \\
\hline BP models variants & $4.3 \%(1$ of 23$) \quad 95.7 \%(22$ of 23$)$ & $100 \%(23$ of 23$)$ & $0 \%$ \\
\hline BP models merging & $0 \%(0$ of 3$) \quad 100 \%(3$ of 3$)$ & $100 \%(3$ of 3$)$ & $0 \%$ \\
\hline Multi-perspective modeling & $100 \%(10$ of 10$) \quad 0 \%(0$ of 10$)$ & $10 \%(1$ of 10$)$ & $90 \%(9$ of 10$)$ \\
\hline
\end{tabular}

Table 7. Consistency nature in relation with the inconsistency source.

\begin{tabular}{lccc}
\hline Inconsistency source & \multicolumn{3}{c}{ Consistency nature } \\
& Syntactic & Semantic & Both \\
\hline BP models merging & $0 \%$ & $100 \%(3$ of 3$)$ & $0 \%$ \\
BP models variants & $0 \%$ & $95,7 \%(22$ of 23$)$ & $4,3 \%(1$ of 23$)$ \\
Multi-perspective modeling & $0 \%$ & $10 \%(1$ of 10$)$ & $90 \%$ (9 of 10$)$ \\
& & & \\
\hline
\end{tabular}

Furthermore, the three approaches (S5, S7 and S8) seeking to tackle the consistency when merging two fragments of BP models chiefly target consistency of a semantic nature as depicted in Table 7. This refers to consistency problems related to behavioral aspects of a BP like the exclusiveness of a pair of activity (i.e. the execution logic such as AND, OR, XOR) or their order of potential occurrence. Fig. 2 and Fig. 3 summarize the relation between the six fundamental activities in inconsistency management, and the three sources of inconsistency.

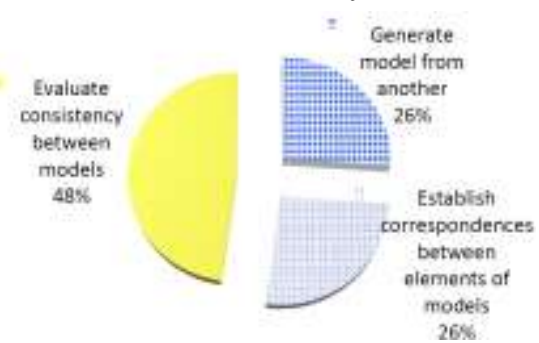

Fig. 2. Activities in inconsistency management when inconsistency source is BP models variants

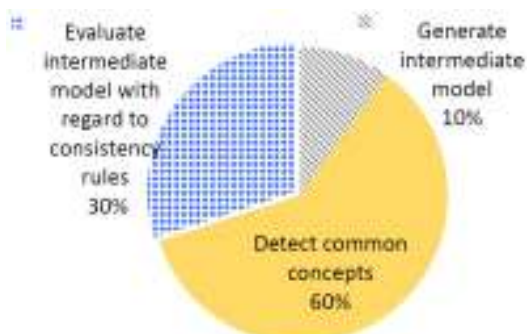

Fig. 3. Activities in inconsistency management when inconsistency source is Multi-perspective modeling

Fig. 2 highlights that the most common activity (48\%) in the literature with respect to the inter-model consistency is its evaluation, known as consistency checking between two or more BP models variants. Fig. 3 shows that managing inconsistency in case of multiperspective modeling consists mainly in detecting common concepts among multiple views $(60 \%)$. Evaluating an intermediate model with regard to consistency rules $(30 \%)$ is also referred as consistency checking in the literature. We also observed that only few concepts are shared between the models when they depict the same system from complementary perspectives. Hence, a partial dependency exists between the BP models. An inter-model consistency problem occurs when a partial or a total (strong) dependency exists between BP models. The former happens in case of multi-perspective modeling, 
whereas the latter appears when many variants of the same BP exist. The source of inconsistency among BP models seems to be the cornerstone of each attempt for categorizing research works dealing with the inter-model consistency issue.

In the following, we attempt to answer the research questions set in section 3.1.

RQ1: We identified three sources of inconsistency among BP models (see Fig. 1). The majority of approaches focus on the variants of the same BP model (64\%). During our analysis of multi-perspective modeling approaches (28\%), we noted that among the 10 primary studies, only one, S27, has focused on the BP as a subject of modeling, i.e. according to multiple perspectives. Unfortunately, the proposed solution is not applicable outside of this primary study (QA2=N, see Table 5). Four others (S1, S2, S3, S6) analyze the enterprise as a whole, offering the BP models among the multiple perspectives. Finally, the five latters (S18, S22, S23, S24, S25) offer multiple perspectives in enterprise modeling, excluding BP models. Hence, it will be promising to overcome the lack of approaches dealing with the consistency among multi-perspective BP models.

RQ2/RQ3: The majority of approaches presented (75\%) focused in the activity-driven diagrams, where a BP is modeled as a sequence of activities by using a single modeling technique. This does not allow capturing all facets of a BP in a comprehensive manner. The need to resorting to different types of diagrams emerges, especially for modeling knowledge intensive BPs. Thereby, mastering the consistency between BP models produced using a variety of modeling techniques becomes essential to guarantee a complete and coherent picture of a BP.

RQ4/RQ5: Only 30.6\% of the studied approaches handle the horizontal consistency. The percentage of approaches seeking for both syntactic and semantic consistency among BP models is limited to $27,8 \%$ ( 10 of 36 ). These results reveal the need for enhancing the other approaches by similar capabilities, when the causes of the inconsistencies call for such capabilities.

RQ6: The most recurrent activity in consistency management applied to BP models variants (Fig. 2) is the evaluation of consistency between models (48\%), also called consistency checking. Hence, it will be beneficial if the inconsistencies between models can be prevented (i.e. managing inconsistencies in early steps of modeling) rather than corrected (i.e. managing inconsistencies at late steps of exploitation).

RQ7/RQ8: $97.2 \%$ of approaches focus on BP models within the same enterprise. $80 \%$ of approaches dealing with the consistency issues in the context of multi-perspective modeling are concerned with a projective type, and hence with a particular enterprise modeling method. It may seem obvious that approaches aiming to master the consistency between inter-enterprise BP models, which often implies heterogonous modeling techniques, are still lacking.

\section{Towards categorizing approaches related to inter-model consistency: A reference framework}

In the light of the results of the SLR and their analysis summarized in the above section 4, the inconsistency source is considered as the basic factor on which we can rely in order to categorize the approaches dealing with the consistency among BP 
models. For each class of approaches, related to a particular source of inconsistency amongst the three sources (the variants of BP models, the multi-perspective modeling and the merging of BP models), we consider in turn other factors which may characterize approaches placed in the same class.

Fig. 4. A Framework towards categorizing approaches focusing on inter-model consistency

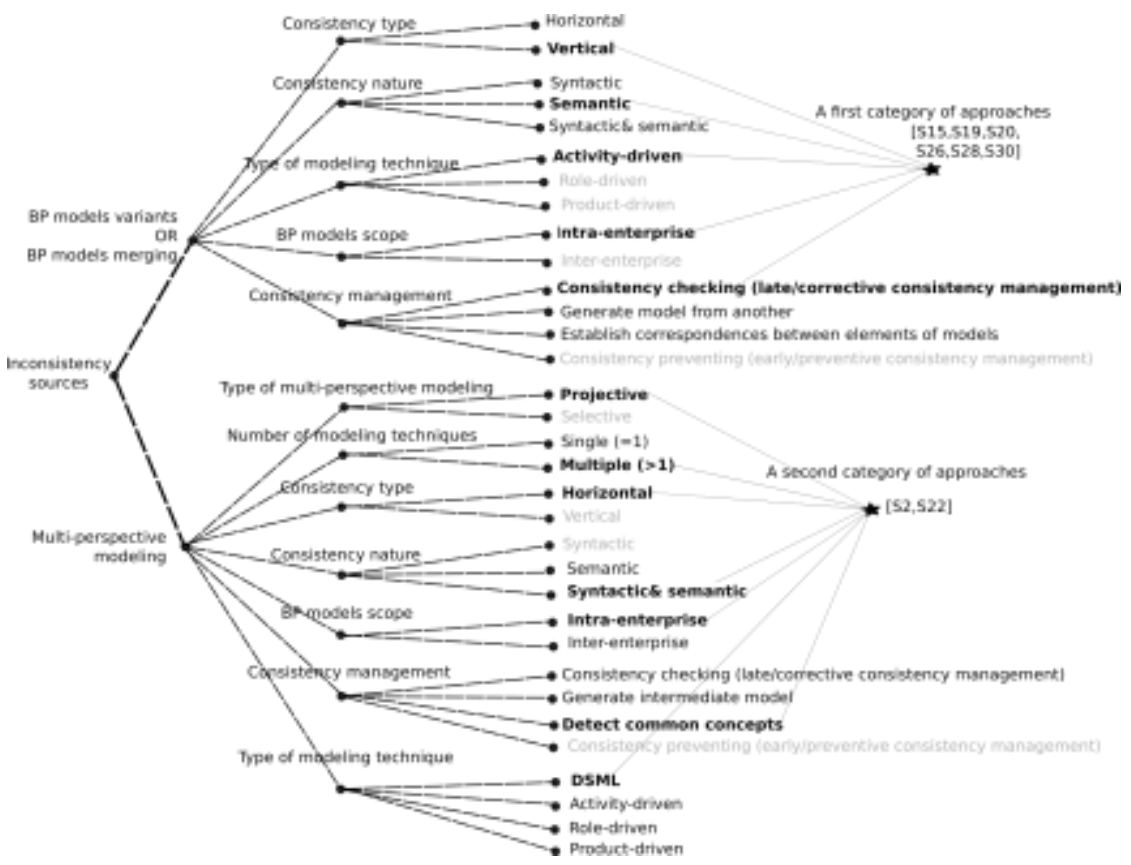

Fig. 4 shows the proposed framework in the form of a tree. We aim that each research work dealing with the issue of consistency among BP models takes place in this framework (which is a first attempt and is candidate to evolution). Values in bold are the most common ones in the literature regarding the corresponding characteristics. The less common values among the studied approaches are shown in gray; together with the values in simple black, they suggest us research challenges. In Fig. 4, we also illustrated the use of this framework, by requesting the approaches offering the indicated values for the search parameters (shown with the gray lines).

\section{Conclusion}

A problem of inter-model consistency can occur when a partial or strong dependency exists between BP models. A partial dependency arises when few concepts are shared between models; this is the case for multi-perspective modeling. A total dependency occurs when it is possible to establish correspondences between all elements involved in the models. Therefore, challenges related to the decomposition (vertical coherence) or the similarity issues between BP models might be also considered as consistency issues.

In this paper, we presented the results gained from undertaking a SLR on consistency 
among BP models with the aim of proposing a framework that facilitates (i) categorizing the plethora of existing approaches and (ii) providing directions for promising new research activities with regard to this topic. We considered a total of 982 papers and extracted from the most relevant scientific sources, of which 41 papers were ultimately analyzed in depth by referring to the Kitchenham's guidelines. The results mainly showed that a special attention must be given to the consistency between multi-perspective BP models, where a lack of approaches has been noticed. The results also revealed that the majority of the existing approaches tackle the consistency checking and thus handle the detected inconsistencies between models (i.e. late/corrective consistency management) rather than preventing them (i.e. early/preventive consistency management). The latter seems to be a promising line of research.

\section{References}

1. Curtis, B., Kellner, M. \& Over, J. (1992), 'Process modelling', Communications of the ACM 35 (9), 75-90.

2. Rolland, C. (1997). A primer for method engineering. Proceedings of the INFormatique des ORganisations et Systemes d'Information et de Décision, Toulouse, France.

3. Rolland, C. (1998). A comprehensive view of process engineering. In Advanced Information Systems Engineering (pp. 1-24). Springer Berlin Heidelberg.

4. Feiler, P. H., \& Humphrey, W. S. (1993). Software process development and enactment: Concepts and definitions. Continuous Software Process Improvement, Second International Conference on the Software Process (pp. 28-40). IEEE.

5. Sandkuhl, K., Stirna, J., Persson, A., \& Wißotzki, M. (2014). Enterprise Modeling. Tackling Business Challenges with the 4EM Method. Springer, 309.

6. Dumas, M., Van der Aalst, W. M., \& Ter Hofstede, A. H. (2005). Process-aware information systems: bridging people and software through process technology. John Wiley \& Sons.

7. Hammer, M., Champy, J. (1993). Le reengineering (Vol. 93). Dunod.

8. Peterson, R. S., Smith, D. B., Martorana, P. V., \& Owens, P. D. (2003). The impact of chief executive officer personality on top management team dynamics: one mechanism by which leadership affects organizational performance. Journal of Applied Psychology, 88(5), 795.

9. Muskens, J., Bril, R. J., \& Chaudron, M. R. (2005). Generalizing consistency checking between software views. 5th Working IEEE/IFIP Conference on Software Architecture (pp. 169-180). IEEE.

10. Hallerbach, A., Bauer, T., \& Reichert, M. (2010). Configuration and management of process variants. In Handbook on Business Process Management 1 (pp. 237-255). Springer.

11. Lucas, F. J., Molina, F., \& Toval, A. (2009). A systematic review of UML model consistency management. Information and Software Technology, 51(12), 1631-1645.

12. Spanoudakis, G., \& Zisman, A. (2001). Inconsistency management in software engineering: Survey and open research issues. Handbook of software engineering and knowledge engineering, 1, 329-380.

13. Nurcan, S. (2012). Ingénierie et Architecture d'Entreprise et des Systèmes d'Information-Concepts, Fondements et Méthodes (Habilitation dissertation, Université Paris 1 Panthéon-Sorbonne).

14. Chapurlat, V. (2007). Vérification et validation de modèles de systèmes complexes: application à la Modélisation d'Entreprise (Habilitation dissertation, Université Montpellier II).

15. Russell, N., van der Aalst, W. M., Ter Hofstede, A. H., \& Wohed, P. (2006). On the suitability of UML 2.0 activity diagrams for business process modelling. In Proceedings of the 3rd Asia-Pacific conference on Conceptual modelling. Vol(53). (pp. 95-104).

16. Mendling, J., Neumann, G., \& Nüttgens, M. (2005). A comparison of XML interchange formats for business process modelling. Workflow handbook, 185-198.

17. Akobeng, A. K. (2005). Understanding systematic reviews and meta-analysis. Archives of disease in childhood, 90(8), 845-848

18. IEEE standard 42010 (IEEE, 2011).

19. Persson, M., Törngren, M., Qamar, A., Westman, J., Biehl, M., Tripakis, S., \& Denil, J. (2013,). A characterization of integrated multi-view modeling in the context of embedded and cyber-physical systems. In 11 th ACM Int. Conference on Embedded Software (p. 10). IEEE Press.

20. Brooks, C., Cheng, C. P., Feng, T. H., Lee, E. A., \& Von Hanxleden, R. (2008). Model engineering using 
multimodeling (No. UCB/EECS-2008-39). California University. Berkeley.

21. Cicchetti, A., Ciccozzi, F., \& Leveque, T. (2012). A hybrid approach for multi-view modeling. Electronic Communications of the european association for the study of science and technology, 50.

22. Broy, M., Feilkas, M., Herrmannsdoerfer, M., Merenda, S., \& Ratiu, D. (2010). Seamless model-based development: From isolated tools to integrated model engineering environments. Proceedings of the IEEE, 98(4), 526-545.

23. Engels, G., Küster, J. M., Heckel, R., \& Groenewegen, L. (2001). A methodology for specifying and analyzing consistency of object-oriented behavioral models. In ACM SIGSOFT Software Engineering Notes (Vol. 26, No. 5, pp. 186-195). ACM.

24. Kitchenham, B., Brereton, O. P., Budgen, D., Turner, M., Bailey, J., \& Linkman, S. (2009). Systematic literature reviews in software engineering-a systematic literature review. Information and software technology, 51(1), 715.

25. Kitchenham, B. (2004). Procedures for performing systematic reviews. Keele, UK, Keele University, 33(2004), $1-26$.

26. Keele, S. (2007). Guidelines for performing systematic literature reviews in software engineering. In Technical report, Ver. 2.3 EBSE Technical Report. EBSE.

27. Governatori, G., \& Sadiq, S. (2008). The journey to business process compliance.

28. Bork, D., \& Karagiannis, D. (2014). Model-driven development of multi-view modeling tools the MuVieMOT approach. In ICSOFT-PT, 2014 (pp. IS-11). IEEE

29. Yan, Z., Dijkman, R., \& Grefen, P. (2012). Business process model repositories-Framework and survey. Information and Software Technology, 54(4), 380-395

30. Hallerbach, A., Bauer, T., \& Reichert, M. (2010). Capturing variability in business process models: the Provop approach. Journal of Software Maintenance and Evolution: Research and Practice, 22(6-7), 519-546.

31. Smirnov, S., Weidlich, M., \& Mendling, J. (2010). Business process model abstraction based on behavioral profiles. In Service-Oriented Computing (pp. 1-16). Springer.

32. Koliadis, G., Vranesevic, A., Bhuiyan, M., Krishna, A., \& Ghose, A. K. (2006). A combined approach for supporting the business process model lifecycle.

33. Gerth, C., Luckey, M., Kuster, J. M., \& Engels, G. (2010,). Detection of semantically equivalent fragments for business process model change management. In IEEE International Conference on Services Computing. (pp. 57-64). IEEE.

34. Zemni, M. A., Mammar, A., \& Ben Hadj Alouane, N. (2014). A Behavior-Aware Systematic Approach for Merging Business Process Fragments. In Engineering of Complex Computer Systems. 19th International Conference on (pp. 194-197). IEEE.

35. Pascalau, E., Awad, A., Sakr, S., \& Weske, M. (2010). On maintaining consistency of process model variants. In Business Process Management Workshops (p. 289-300). Springer.

36. Weidlich, M., Mendling, J., \& Weske, M. (2011). Efficient consistency measurement based on behavioral profiles of process models., IEEE Trans. on Software Engineering, 37(3), 410-429.

37. Koschmider,A., \& Blanchard,E. (2007). User assistance for business process model decomposition. In 1st IEEE Int. Conf. on Research Challenges in Information Science (p. 445-454).

38. Koliadis, G., \& Ghose, A. (2007). Verifying semantic business process models in inter-operation. In IEEE International Conference on Services Computing, 2007. (p. 731-738).

39. Milani, F., Dumas, M., Ahmed, N., \& Matulevičius, R. (2013). Modelling Families of Business Process Variants: A Decomposition Driven Method. arXiv preprint arXiv:1311.1322.

40. Dijkman, R., Gfeller, B., Küster, J., \& Völzer, H. (2011). Identifying refactoring opportunities in process model repositories. Information and Software Technology, 53(9), 937-948.

41. Lu, R., Sadiq, S., Governatori, G., \& Yang, X. (2009). Defining adaptation constraints for business process variants. In Business Information Systems (pp. 145-156). Springer.

42. Rastrepkina, M. (2010). Managing variability in process models by structural decomposition. In Business Process Modeling Notation (pp. 106-113). Springer.

43. Pascalau, E., \& Rath, C. (2010). Managing business process variants at eBay. In Business Process Modeling Notation (pp. 91-105). Springer Berlin Heidelberg.

44. Bork, D., Buchmann, R., \& Karagiannis, D. (2015). Preserving Multi-view Consistency in Diagrammatic Knowledge Representation. In Knowledge Science, Engineering and Management (pp. 177-182). Springer International Publishing.

45. Cheng-Leong, A., Li Pheng, K., \& Keng Leng, G. R. (1999). IDEF*: a comprehensive modelling methodology for the development of manufacturing enterprise systems. International Journal of Production Research, 37(17), 3839-3858.

46. Chen-Burger, Y. H. (2001). Knowledge sharing and inconsistency checking on multiple enterprise models. In International Joint Conference on Artificial Intelligence, Knowledge Management and Organizational 
Memories Workshop, Seattle, Washington, USA

47. Koehler, J., Tirenni, G., \& Kumaran, S. (2002). From business process model to consistent implementation: A case for formal verification methods. In Enterprise Distributed Object Computing Conference. Proceedings. Sixth International (pp. 96-106). IEEE.

48. Worzberger, R., Kurpick, T., \& Heer, T. (2008). On correctness, compliance and consistency of process models. In Workshop on Enabling Technologies: Infrastructure for Collaborative Enterprises. IEEE 17th (pp. 251252). IEEE.

49. Dijkman, R., Dumas, M., Garcia-Banuelos, L., \& Käärik, R. (2009). Aligning business process models. In IEEE International EDOC Conference. (pp. 45-53). IEEE

50. Lu, R., \& Sadiq, S. (2007). On the discovery of preferred work practice through business process variants. In Conceptual Modeling-ER. (pp. 165-180). Springer.

51. Gulden, J., \& Frank, U. (2010). MEMOCenterNG-A full-featured modeling environment for organization modeling and model-driven software development. In 22nd International Conference on Advanced Information Systems Engineering, Hammamet, Tunisia.

52. Delen, D., \& Benjamin, P. C. (2003). Towards a truly integrated enterprise modeling and analysis environment. Computers in Industry, 51(3), 257-268.

53. Leist, S., \& Zellner, G. (2006). Evaluation of current architecture frameworks. In Proceedings of the 2006 ACM symposium on Applied computing (pp. 1546-1553). ACM.

54. Shunk, D. L., Kim, J. I., \& Nam, H. Y. (2003). The application of an integrated enterprise modeling methodology - FIDO - to supply chain integration modeling. Computers \& industrial engineering, 45(1), 167193.

55. Fang, X., Liu, L., \& Liu, X. (2015). Analyzing the Consistency of Business Process Based on Behavioral Petri Net. International Journal of u-and e-Service, Science and Technology, 8(2), 25-34.

56. Weidlich, M., Dijkman, R., \& Mendling, J. (2010). The ICoP framework: Identification of correspondences between process models. In 22nd International Conference on Advanced Information Systems Engineering, Hammamet, Tunisia.

57. Koubarakis, M., \& Plexousakis, D. (2002). A formal framework for business process modelling and design. Information Systems, 27(5), 299-319.

58. Vanderfeesten, I., Reijers, H. A., Mendling, J., van der Aalst, W. M., \& Cardoso, J. (2008). On a quest for good process models: the cross-connectivity metric. In CAISE'2008 (pp. 480-494). Springer.

59. Martens, A. (2005). Consistency between executable and abstract processes. In e-Technology, e-Commerce and e-Service. Proceedings. The 2005 IEEE International Conference on (pp. 60-67). IEEE.

60. Decker, G., \& Weske, M. (2007). Behavioral consistency for B2B process integration. In Advanced Information Systems Engineering (pp. 81-95). Springer.

61. Fang, X., Wang, M., \& Yin, Z. (2013). Behavior Consistency Analysis Based on the Behavior Profile about Transition Multi-Set of Petri Net. Przegląd Elektrotechniczny, 89(1b), 171-173.

62. De Medeiros, A.A., van der Aalst, W. M., \& Weijters, A. J. M. M. (2008). Quantifying process equivalence based on observed behavior. Data \& knowledge engineering, 64(1), 55-74.

63. Weidlich, M., \& Mendling, J. (2012). Perceived consistency between process models. Information Systems, 37(2), 80-98.

64. Niemann, M., Siebenhaar, M., Schulte, S., \& Steinmetz, R. (2012). Comparison and retrieval of process models using related cluster pairs. Computers in Industry, 63(2), 168-180.

65. Küster,J.M., Gerth,C., Förster,A., \& Engels,G. (2008). Detecting and resolving process model differences in the absence of a change log. In Business Process Management (p.244-260). Springer

66. Dijkman,R., Dumas,M., \& García-Bañuelos, L. (2009). Graph matching algorithms for business process model similarity search. In Business Process Management (pp. 48-63). Springer.

67. Van der Aalst, W. M., De Medeiros, A. A., \& Weijters, A. J. M. M. (2006). Process equivalence: Comparing two process models based on observed behavior (p. 129-144). Springer.

68. Li, C., Reichert, M., \& Wombacher, A. (2008,). Discovering reference process models by mining process variants. In Web Services. IEEE International Conference on (pp. 45-53). IEEE.

69. Zachman, J.A. (1987). A Framework for Information Systems Architecture. IBM Systems Journal, 1987, 26(3)

70. S. Nurcan, C. Rolland. (1999). Using EKD-CMM electronic guide book for managing change in organisations. Proceedings of the 9th European-Japanese Conference on Information Modeling and Knowledge Bases, Iwate, Japan, p.105-123.

71. F. Daoudi, S. Nurcan. (2007), A benchmarking framework for methods to design flexible business processes, Special issue of the Software Process: Improvement and Practice, Journal on Business Process Management, Development and Support, vol. 12, n. 1. 